\title{
Daily physical activity assessment with accelerometers: new insights and validation studies.
}

Citation for published version (APA):

Plasqui, G., Bonomi, A. G., \& Westerterp, K. R. (2013). Daily physical activity assessment with accelerometers: new insights and validation studies. Obesity Reviews, 14(6), 451-462. https://doi.org/10.1111/obr.12021

Document status and date:

Published: 01/06/2013

DOI:

10.1111/obr.12021

Document Version:

Publisher's PDF, also known as Version of record

Document license:

Taverne

Please check the document version of this publication:

- A submitted manuscript is the version of the article upon submission and before peer-review. There can be important differences between the submitted version and the official published version of record.

People interested in the research are advised to contact the author for the final version of the publication, or visit the DOI to the publisher's website.

- The final author version and the galley proof are versions of the publication after peer review.

- The final published version features the final layout of the paper including the volume, issue and page numbers.

Link to publication

\footnotetext{
General rights rights.

- You may freely distribute the URL identifying the publication in the public portal. please follow below link for the End User Agreement:

www.umlib.nl/taverne-license

Take down policy

If you believe that this document breaches copyright please contact us at:

repository@maastrichtuniversity.nl

providing details and we will investigate your claim.
}

Copyright and moral rights for the publications made accessible in the public portal are retained by the authors and/or other copyright owners and it is a condition of accessing publications that users recognise and abide by the legal requirements associated with these

- Users may download and print one copy of any publication from the public portal for the purpose of private study or research.

- You may not further distribute the material or use it for any profit-making activity or commercial gain

If the publication is distributed under the terms of Article $25 \mathrm{fa}$ of the Dutch Copyright Act, indicated by the "Taverne" license above, 


\title{
Obesity Diagnostic
}

\section{Daily physical activity assessment with accelerometers: new insights and validation studies}

\author{
G. Plasquii ${ }^{1}$ A. G. Bonomi ${ }^{2}$ and K. R. Westerterp ${ }^{1}$
}

${ }^{1}$ Human Biology Department, NUTRIM School for Nutrition, Toxicology and Metabolism, Maastricht University Medical Centre +, Maastricht, the Netherlands; ${ }^{2}$ Personal Health Solutions, Philips Research laboratories, Eindhoven, the Netherlands

Received 27 September 2012; revised 21 December 2012; accepted 7 January 2013

Address for correspondence: Dr G Plasqui, Department of Human Biology, Maastricht University, PO Box 616, 6200 MD Maastricht, the Netherlands.

E-mail: g.plasqui@maastrichtuniversity.nl

\begin{abstract}
Summary
The field of application of accelerometry is diverse and ever expanding. Because by definition all physical activities lead to energy expenditure, the doubly labelled water (DLW) method as gold standard to assess total energy expenditure over longer periods of time is the method of choice to validate accelerometers in their ability to assess daily physical activities. The aim of this paper was to provide a systematic overview of all recent (2007-2011) accelerometer validation studies using DLW as the reference. The PubMed Central database was searched using the following keywords: doubly or double labelled or labeled water in combination with accelerometer, accelerometry, motion sensor, or activity monitor. Limits were set to include articles from 2007 to 2011, as earlier publications were covered in a previous review. In total, 38 articles were identified, of which 25 were selected to contain sufficient new data. Eighteen different accelerometers were validated. There was a large variability in accelerometer output and their validity to assess daily physical activity. Activity type recognition has great potential to improve the assessment of physical activity-related health outcomes. So far, there is little evidence that adding other physiological measures such as heart rate significantly improves the estimation of energy expenditure.
\end{abstract}

Keywords: Accelerometry, activity monitor, doubly labelled water, motion sensor.

obesity reviews (2013) 14, 451-462

\section{Introduction}

Given the importance of regular physical activity in maintaining health, the quest for valid methodologies to measure physical activities under the unconfined conditions of daily life is ever expanding. Activity monitors or accelerometers can objectively capture body movement and provide information on the total amount, intensity, duration and frequency of physical activities performed. As a consequence, applying accelerometry as a tool to assess daily physical activities is a rapidly evolving field of research. Early piezo-resistive accelerometers that were able to capture static acceleration such as the gravitational field were hampered by a large battery unit and limited battery life (1). Many motion sensors therefore switched from piezo-resistive to piezoelectric accelerometers, which required less battery power and hence were considerably smaller in size and allowed data capturing over longer periods of time up to 3 weeks (2). Over recent years, a particular interest has occurred in capturing not only body movement but also the type of activity performed. The importance of activity recognition is supported by epidemiological data showing that sedentary behaviour is a risk factor for diseases, independent of the level of physical activity $(3,4)$. Those findings generated the need to objectively assess postures and therefore modern piezo-resistive and capacitive accelerometers that combine the advantage of measuring the gravitational field along with small size and weight and long battery life have been developed. Measuring the gravitational field allows to determine the orientation of the body and consequently body posture. In order to measure the type of physical activity, there is also 
a need to capture body movement at a high frequency and to store raw unprocessed data. The memory capacity of most accelerometers has evolved equally rapid allowing the collection of raw acceleration data (e.g. at 30-100 Hz) over several weeks.

The definition of physical activity provided by Caspersen et al. states that physical activity comprises any body movement, produced by skeletal muscles, that results in energy expenditure (EE) (5). Indeed, the laws of physics dictate that energy is required to perform (mechanical) work. The direct consequence is that body movement, as assessed by an accelerometer, should lead to an increase in EE, and a relation between accelerometer output and an independent measure of EE, such as doubly labelled water (DLW), should be present.

As shown earlier, many, although not all, accelerometers perform poorly when compared to the gold standard of DLW (6). Therefore, some researchers have attempted to increase the accuracy of activity monitors to assess activityrelated EE by adding other physiological measures such as body temperature or heart rate (HR).

Given the large amount of activity monitors available, it has become a major challenge for researchers to keep up with the new developments in the field and to decide which device to use and why. This paper aims to summarize all recent literature on the validity of different accelerometers and to provide an overview of some technical characteristics of these accelerometers. Given the relation between body movement and EE, as dictated by the laws of physics, and the requisite that physical activity needs to be measured under unconfined conditions, DLW-assessed EE was chosen as the reference technique.

\section{Methods}

The PubMed Central database (U.S. National Institutes of Health free digital archive of biomedical and life sciences journal literature) was searched using the following keywords: doubly or double labelled or labeled water in combination with accelerometer, accelerometry, motion sensor or activity monitor. Limits were set to include articles published between January 2007 and December 2011. Studies published before 2007 have been covered in a previous review (6). In total, 38 articles were identified of which 25 contained new data on the validity of the accelerometer as compared to DLW. Thirteen articles were not included because no new data were included (e.g. review article) or no comparison was made between accelerometry and DLW (6-18).

\section{Results}

Eighteen different accelerometers from 15 different brands were identified (Table 1). For the Actigraph (Actigraph, Pensacola, FL, USA), SenseWear (BodyMedia, Inc., Pittsburgh,
PA, USA) and Tracmor (Philips New Wellness Solutions, Eindhoven, the Netherlands), two different versions of the accelerometer were validated. Five out of the 18 monitors were included and briefly described in a previous review (6). The remaining activity monitors that have been validated in daily life over the past 5 years are briefly described below. Table 1 provides an overview of all validated accelerometers with details about the number of axes, wearing position, size, weight, sampling frequency, frequency response and dynamic range, when provided. Data about the accelerometer were retrieved from the validation study included in Table 2 and from additional literature and company websites when available. The results in Table 1 show that only few companies provide information about the frequency response and dynamic range of the accelerometer.

\section{Description of accelerometers}

The $3 \mathrm{dNX}^{\mathrm{TM}}$ (BioTel Ltd, Bristol, UK) is a triaxial accelerometer weighing $93 \mathrm{~g}$ including the battery. It contains three piezoelectric ADXL210E sensors (Analog Devices, Surrey, UK) (19). The Accusplit AX120 is a hip-worn spring-lever pedometer (Accusplit, San Jose, CA, USA). The Dynastream AMP-331 is a triaxial accelerometer (Cochrane, Alberta, Canada) positioned on the back of the ankle which measures the forward and vertical accelerations to determine the position of the foot in space $(20,21)$. The Actiheart (Cambridge Neurotechnology Ltd, Cambridge, UK) is a combined HR and movement sensor. The main component is $7 \mathrm{~mm}$ thick with a diameter of $33 \mathrm{~mm}$ and houses a movement sensor, a rechargeable battery, a memory chip and other electronics. A wire of approximately $100 \mathrm{~mm}$ length runs to a smaller $(5 \times 11 \times 22 \mathrm{~mm})$ clip. An 8 -min step test at a step height of $20 \mathrm{~cm}$ is used to provide individual calibration of HR to physical activity intensity $(22,23)$. The SenseWear Pro Armband (BodyMedia, Inc., Pittsburgh, PA, USA) is a multiple sensor device collecting data from a skin temperature sensor, near-body temperature sensor, heat flux sensor, galvanic skin response sensor and a biaxial accelerometer. These signals are combined to assess the type and intensity of an activity. Together with information about gender, age, height and weight, EE is estimated. The SenseWear Mini (Model: MF-SW) is a newer and smaller version of the SenseWear Armband. The Mini operates in a similar manner but includes a three-axis accelerometer rather than a two-axis accelerometer $(24,25)$. The ActivPAL (PAL Technologies Ltd, Glasgow, UK) uses a uniaxial accelerometer sampling at $10 \mathrm{~Hz}$ to produce signals reflecting thigh inclination and movement. The software classifies positions and activities into three categories: lying or sitting, standing and stepping. Cadence and number of steps taken describes the intensity and volume of activity. The software assigns each activity an estimated energy cost in metabolic equivalents (METs), which are then summated over the 


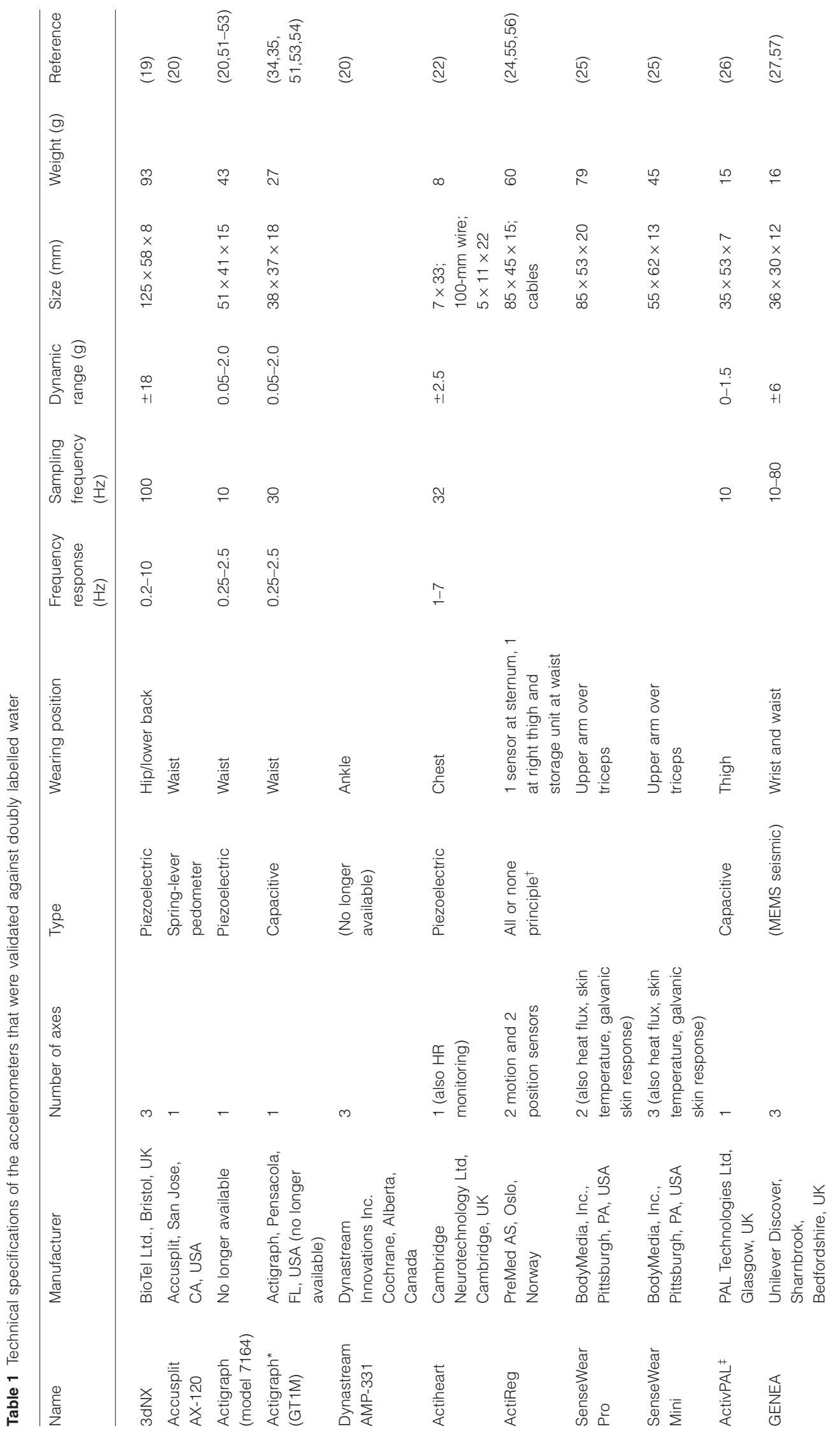




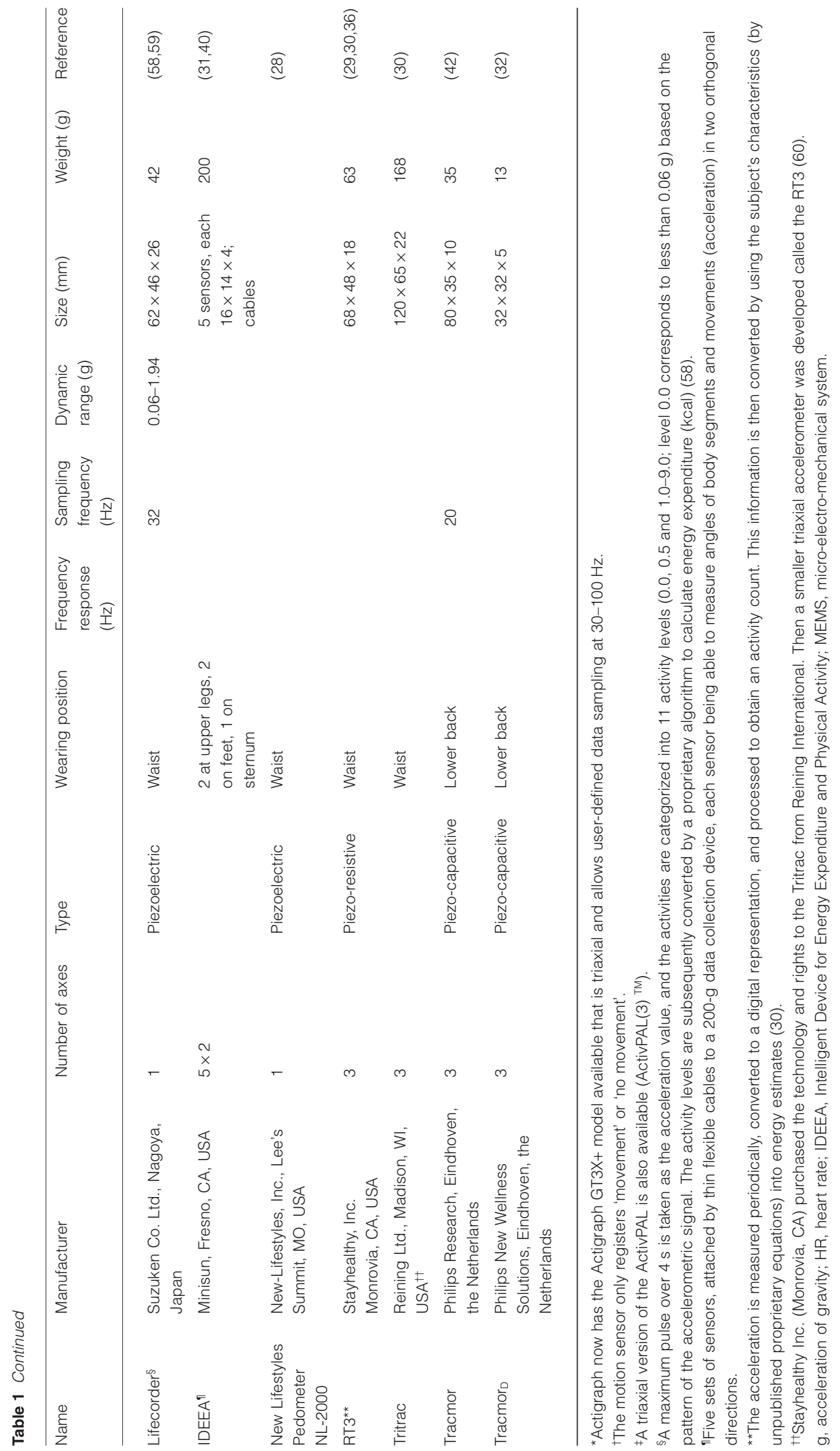




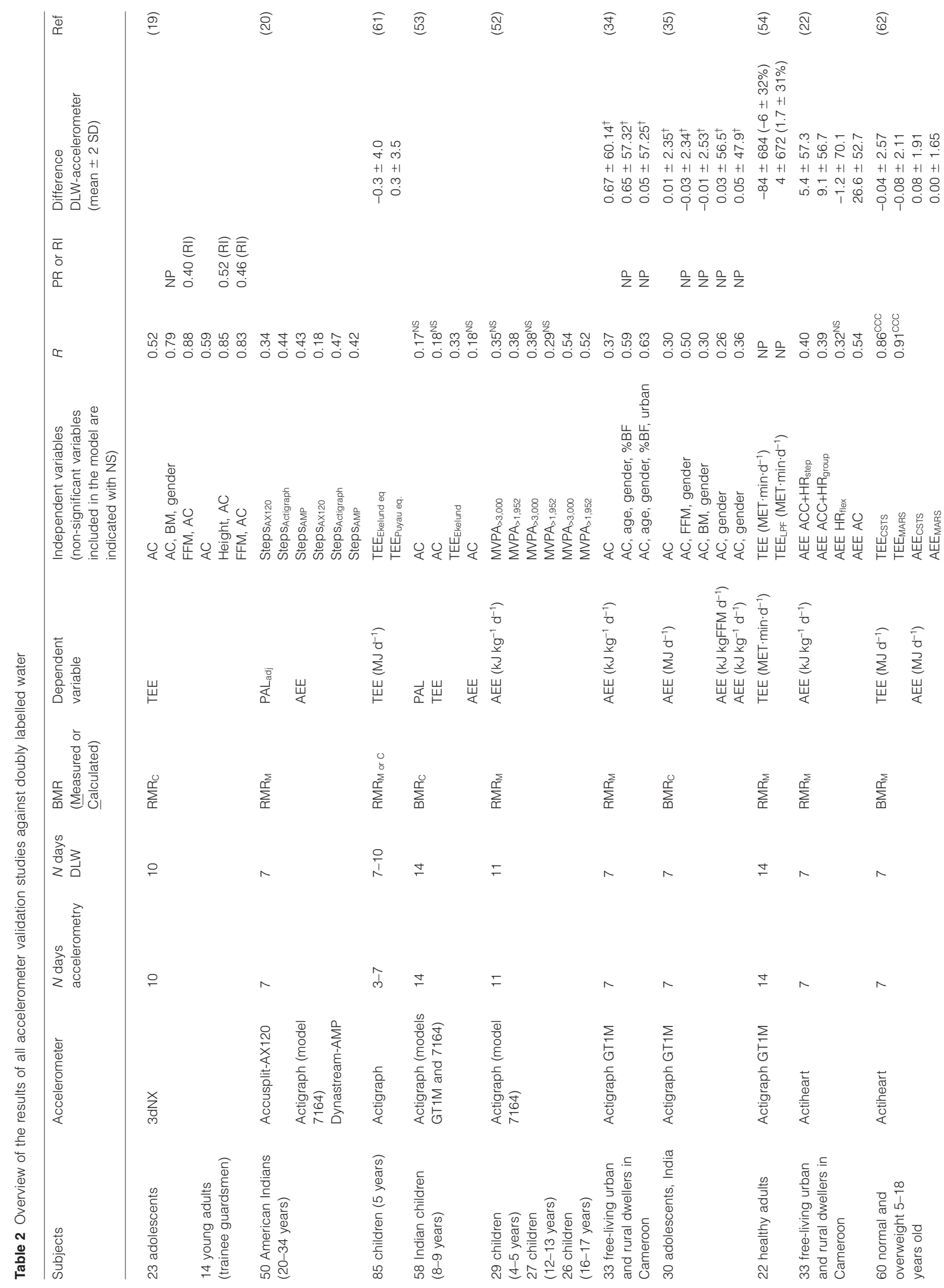




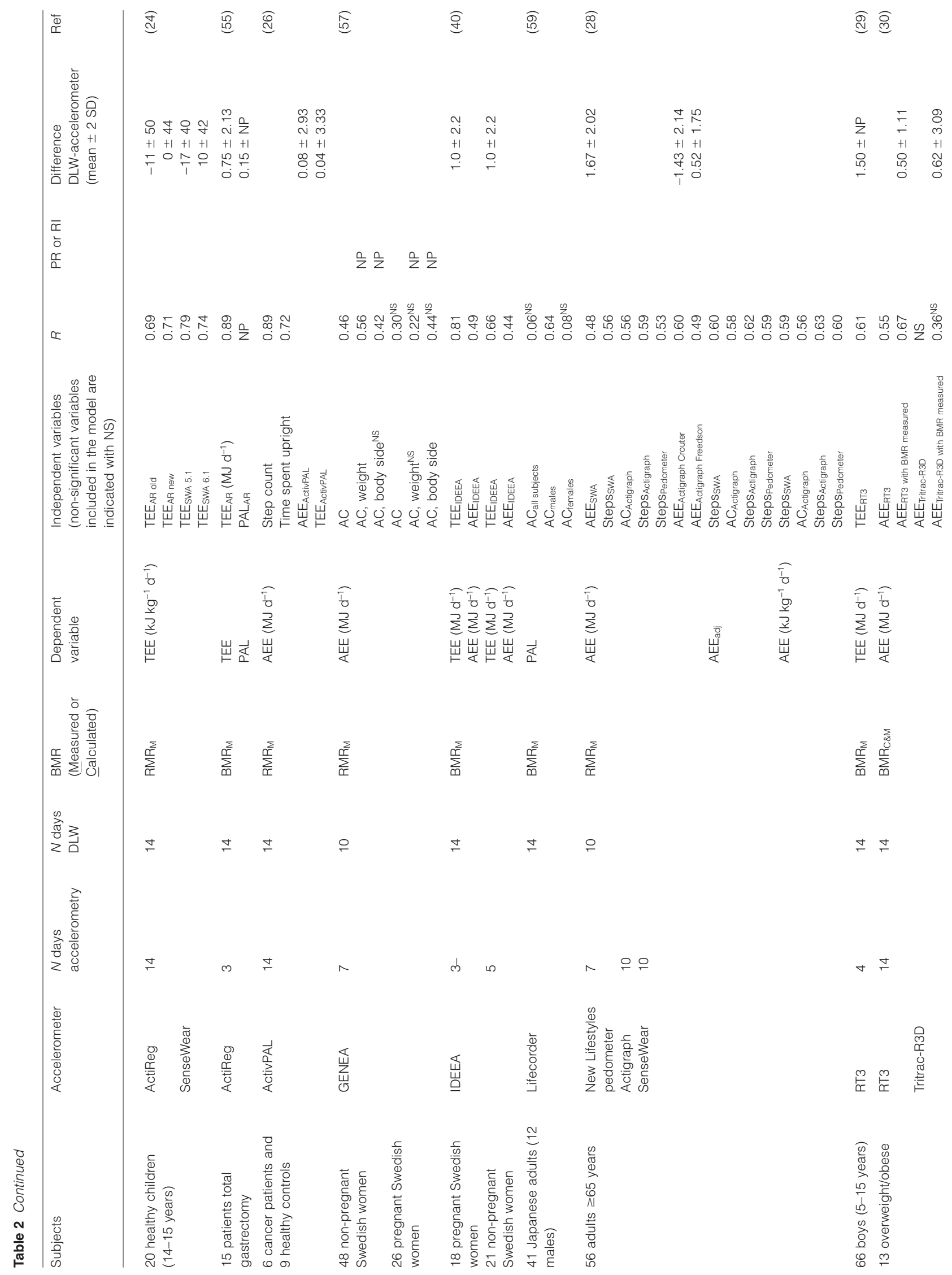




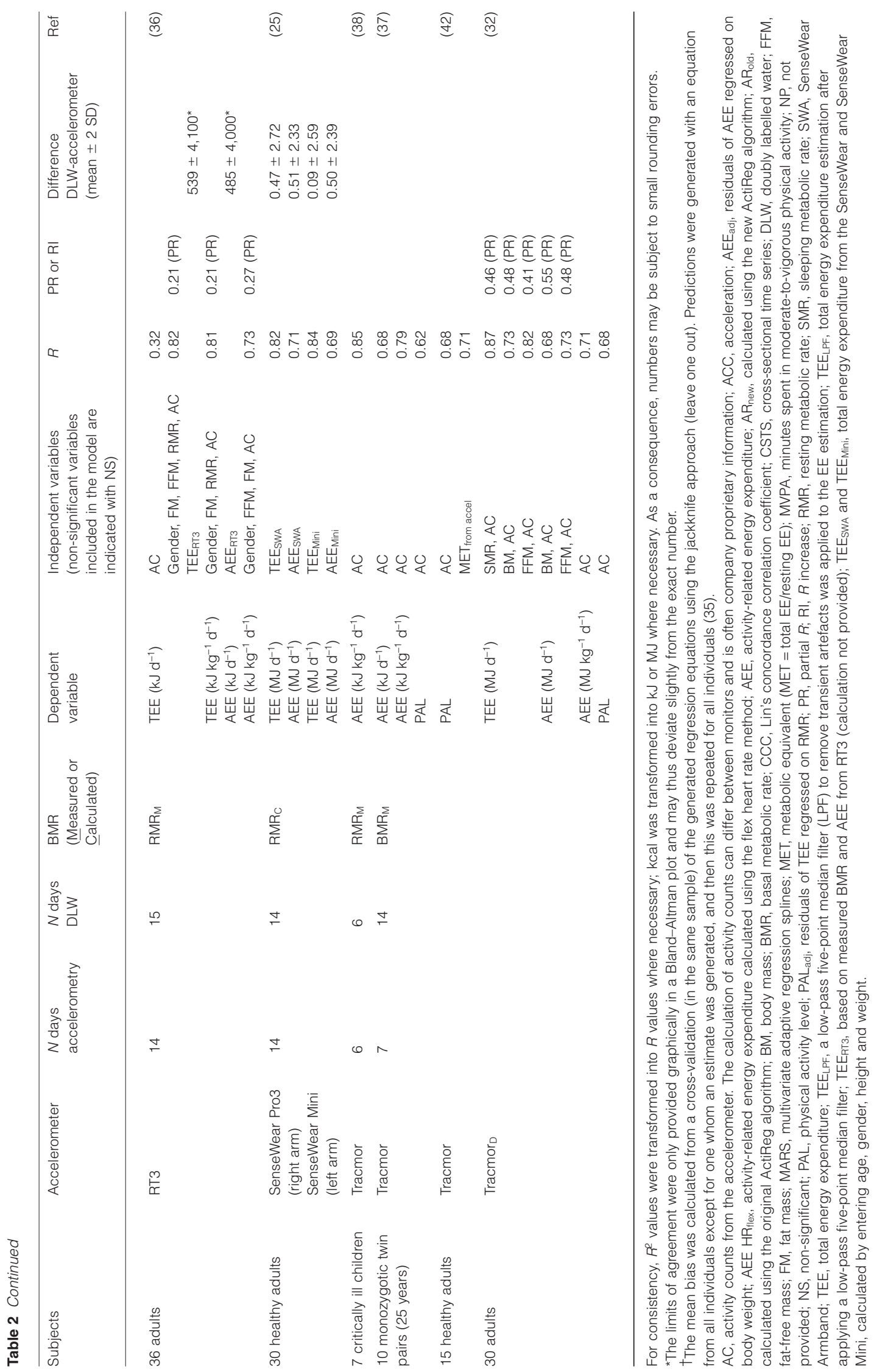


assessment period to derive a value in MET.hours (h) that reflects overall free-living EE (26). The GENEA is a triaxial seismic acceleration sensor (STMicroelectronics, Geneva, Switzerland). It can be easily worn at multiple locations on the body (e.g. wrist, waist, ankle). The GENEA has $500 \mathrm{MB}$ of memory and can store $\sim 8 \mathrm{~d}$ of data in raw mode (at $80 \mathrm{~Hz}$ ). Users have the ability to select user-defined sample frequencies ranging from 10 to $80 \mathrm{~Hz}$ (27). The New Lifestyles pedometer (NL-2000, New-Lifestyles, Inc., Lee's Summit, MO, USA) is a pedometer with a 7-d memory and was used to monitor steps per day, worn on the left hand side of a waist-worn elastic belt (28). The RT3 (Stayhealthy, Inc., Monrovia, CA, USA) is a triaxial piezo-resistive accelerometer. Physical activity related energy expenditure is derived from the magnitude of the vectors of the three axes $(x$-, $y$ - and $z$-axis) using the RT3 software package. Subject's characteristics (weight, height, age, gender) are entered when the monitor is initialized $(29,30)$. The Intelligent Device for Energy Expenditure and Activity (IDEEA, Minisun, Fresno, CA, USA) consists of five small sensors (each $16 \times 14 \times 4 \mathrm{~mm}$, approximately the size of a small postage stamp) that are attached to the body and by flexible cables to a small 200-g data collection device (microcomputer) that can be worn on the belt. The basic working principle of an IDEEA is the following: the IDEEA system monitors body and limb motions constantly through five sensors attached to the chest, thighs and feet. The different combinations of signals from those five sensors represent different physical activities, which are coded as 32 different numbers for 32 activities (31). The Tracmor ${ }_{D}$ (Philips NewWellness Solutions, Eindhoven, the Netherlands) was based on the research device Tracmor $(2,6)$. The device is a small, lightweight instrument that is waterproof up to $30 \mathrm{~m}$ depth, and has a battery life of 3 weeks and an internal memory that can store data for up to 22 weeks (32). The Actigraph/ CSA/MTI (first known as CSA, Computer Science Applications model 7164; later known as MTI, Manufacturing Technology Incorporated, Fort Walton Beach, FL, USA; now known as Actigraph) is one of the most validated and used activity monitors in the literature. It was a small, lightweight, uniaxial accelerometer detecting accelerations from 0.05 to $2 \mathrm{~g}$. In the mid-2000s Actigraph replaced the model AM7164 by the GT1M and with that switched from a piezoelectric to a capacitive sensor (33). In 2009, Actigraph released the model GT3X, their first triaxial accelerometer (33). At the time of this review, a DLW validation of this model was not yet available.

\section{Accelerometer validity}

Table 2 summarizes the results from all validation studies, including the population studied, the dependent variables used, correlations and partial correlations when available, and mean differences between DLW-derived EE and the accelerometer. The dependent variables used are total energy expenditure (TEE), activity-related energy expenditure (AEE) or physical activity level (PAL). Independent variables vary between studies, but accelerometer output is most commonly expressed as 'activity counts'. Some studies only mentioned calculated EE based on activity monitor output and subjects' characteristics. Other studies report independent variables such as minutes spent in moderate to vigorous physical activity (Actigraph) or time spent upright (ActivPAL).

When the independent variables are activity counts and/or subject characteristics, the study usually mentions correlations (and in some cases a partial $R$ or $R$ increase). From these studies, a new prediction equation can be developed when the regression coefficients are provided. When a mean difference between DLW-derived and accelerometer-derived TEE or AEE is provided, the prediction equation was previously developed in a different sample (sometimes a proprietary equation included in the activity monitor). There are two exceptions. In the studies of Assah et al. (34) and Corder et al. (35), the equation was developed in a certain sample and cross-validated in the same sample using the jackknife (leave-one-out) approach. Hence, these two studies mention the correlations with the independent variables (e.g. activity counts, body mass, gender) as well as a mean difference $( \pm 2 \mathrm{SD})$. Mean differences in TEE or AEE between DLW and the accelerometer were often small on the group level, but the limits of agreement $( \pm 2 \mathrm{SD})$ were usually large.

The most validated accelerometer was the Actigraph, followed by the Tracmor. Observed correlations between PAL and activity counts vary between 0.06 (Lifecorder) and 0.68 (Tracmor ${ }_{\mathrm{D}}$ ). Interpreting correlations between AEE or TEE and activity counts becomes more difficult as body mass and other characteristics are the main determinants of EE. Thus, a partial correlation or an $R$ increase is needed. This was only reported in three studies $(19,32,36)$. Output from the $3 \mathrm{dNX}$ accelerometer significantly increased the prediction of TEE in addition to fat-free mass (FFM) (19). The Tracmor significantly contributed to the prediction of TEE after correcting for sleeping metabolic rate, body mass or FFM (32). Likewise, the RT3 significantly contributed to the prediction of TEE and AEE after correction for subject characteristics. When AEE is expressed per kg body mass, correlations with activity counts vary between 0.37 (Actigraph) (34) and 0.79 (Tracmor) (37) or even 0.85 (Tracmor), but the latter was in a small population of seven critically ill children (38).

\section{Discussion}

The aim of the current paper was to review all recent validation studies of accelerometers against DLW in order to guide researchers in their selection of an appropriate 
accelerometer for a specified research goal. Tables 1 and 2 show the large variability in types of accelerometers, how accelerometer output is provided, and their validity to assess daily physical activities.

Where DLW provides an average measure of EE over a period of 1-3 weeks, accelerometers capture actual body movement and are able to provide more detailed information about the physical activity pattern. Advancements in sensor technologies have caused a rapid development of different accelerometer types with different sensor specifications (Table 1). The result is a vast amount of available literature on accelerometers, sometimes with unsupported (commercial) validity claims.

\section{Activity type monitoring}

One of the most noticeable developments over recent years is the evolution to using more piezo-resistive and capacitive sensors. Given that piezoelectric sensors do not respond to static acceleration, i.e. unable to detect the field of gravity, these can not be used to identify body postures such as lying or standing. Piezo-resistive or capacitive sensors measure the gravitational field as $1 \mathrm{~g}$, and hence the output of the sensor is related to posture. These types of sensors are able to provide additional information on activity types. The best wearing position for an accelerometer to assess daily life physical activity is as close as possible to the centre of mass, hence the lower back or hip. Using a single accelerometer placed at the lower back, Bonomi et al. were able to identify six different activity types, i.e. lying, sitting/ standing, active standing, walking, running and cycling. Only the differentiation between standing and sitting could not be achieved with a single accelerometer at this position (39). Multiple sensor systems, such as the IDEEA monitor, can solve this problem, but greatly reduce wear ability and practicality and failure rate can be high. As a consequence, monitoring over longer periods of time becomes difficult $(31,40)$. The ActivPAL, attached to the upper side of the thigh using an adhesive dual layer hydrogel, is also capable of differentiating between sitting, standing and walking.

The interest in identifying postures and activity types may be partly inducted by literature showing the health risk of sedentary behaviour, independent of the physical activity level $(3,4,41)$. Accurate identification of, for example, sitting behaviour may lead to a better prediction of certain cardio-metabolic and inflammatory outcomes than physical activity alone. In addition, Bonomi et al. showed that identification of activity types led to a better estimation of daily EE than just using activity counts (42).

\section{Accelerometer's technical specifications and computational methods}

Table 1 shows, when provided by the manufacturer, more detailed information about the frequency response, sam- pling time and dynamic range of the different accelerometers. This is essential information because selection of the correct frequency range and amplitude will considerably reduce 'noise' as a consequence of those accelerations not arising from human movement but from external sources such as vehicles (1). Already in 1985, it was demonstrated that $99 \%$ of the acceleration power in gait is concentrated below $15 \mathrm{~Hz}$ (43). The frequency range of daily activities, performed on a force platform, was shown to be between 0.3 and $3.5 \mathrm{~Hz}$ (44). For an accelerometer worn at the waist level, an amplitude range of -6 to $+6 \mathrm{~g}$ will suffice (1). Unfortunately, most manufacturers do not provide the specifications of the accelerometers. In addition, low- and high-pass frequency filters are often used to limit the frequency response within specific boundaries. Most devices contain proprietary formulas to calculate activity counts and/or EE. The consequence is that data, such as activity counts, are not comparable between devices, and hence between studies. Other commonly used outcome measures such as time spent in moderate physical activity are also not uniformly comparable between devices because there is no consensus on accelerometer cut-off points. Generally accepted are the cut-off points of $<3$ MET for low intensity, 3-6 MET for moderate intensity, and 6 MET or more for vigorous intensity. The difficulty, however, is to accurately translate activity monitor output to the correct METs. With the collection of raw data and the use of accelerometers sensitive to static acceleration, the signal could also be expressed as a common metric such as acceleration relative to the local acceleration due to gravity $(\mathrm{g})$. Even then, validity of the accelerometer in daily life can only be tested against an independent technique, such as DLW, as the recorded ' $g$ forces' do not necessarily arise from human movement and can be dependent on the dynamic range of the accelerometer. A dynamic range that is too narrow may saturate the acceleration signal during high-intensity movement. Heil recently published recommendations for collecting, processing and reporting physical activity data collected with accelerometers (45). As potential physical activity outcomes, movement, time, EE and activity type-based variables were suggested. All of these could indeed be seen as a relevant health outcome, but the prerequisite is that the monitor used provides accurate data on these variables. For example, time spent in moderate physical activity is highly dependent on the cut-off points used, which vary between and even within accelerometers depending on the study referred to (46). Again, the problem arises that no independent validation technique is available to validate these outcomes in daily life. For example, there is no good reference technique available to assess 'activity types' in daily life, except for direct observation that is not feasible over longer periods of time and without affecting activity behaviour. Obviously, extensive laboratory testing, mimicking conditions 
of daily life, can greatly contribute to validity testing of the accelerometer.

\section{The importance of doubly labelled water measurements}

Not all researchers agree that DLW is the best technique to validate accelerometers as it provides a measure of $\mathrm{EE}$ and not movement. Undoubtedly, both techniques have their own (dis)advantages and can be used complementarily. Where an accelerometer can provide a day-to-day profile of physical activity, DLW provides a measure of TEE over 7-14 d. Clearly, body movement does not equal EE, but by definition body movement will always result in EE. Therefore, DLW is an accurate and independent technique to assess the validity of motion sensors in daily life. Obviously, like all analytical techniques, DLW measurements are prone to error. The difference in DLW-assessed TEE compared to TEE as measured in a respiration chamber was $0 \pm 6 \%$ (mean $\pm \mathrm{SD})$ in our laboratories (47), which was in agreement with data from Schoeller et al. $(1 \pm 7 \%)$ (48). When AEE is used as the dependent variable, the accuracy depends on the correct measurement of TEE, basal metabolic rate (BMR) and diet-induced thermogenesis (DIT). When BMR is calculated instead of measured, the accuracy of calculated AEE will be affected. DIT is mainly determined by the energy content and the protein fraction of the food and is on average $10 \%$ of TEE for subjects in energy balance, consuming a mixed diet (49).

Those accelerometers that contain proprietary formulas to calculate EE have the major disadvantage that the contribution of accelerometer output to the explained variation is unknown. It then becomes impossible for researchers to evaluate whether the accelerometer has any added value to a simple prediction of EE by using just body mass, height, gender and age. Table 2 shows that many of the accelerometers tested perform badly when compared to DLW-assessed EE. When estimates of EE from the accelerometer are correlated with EE from DLW, most of the explained variations will arise from subject characteristics. As previously shown, subject characteristics alone can already explain $64 \%$ of the variation in total $\mathrm{EE}$ in a population of healthy subjects (2).

\section{Addition of extra sensors}

Some researchers have investigated the effect of adding other physiological measures to the acceleration signal to become more accurate predictions of EE. The SenseWear also measures skin temperature, galvanic skin response, and heat flux, and the Actiheart includes HR monitoring in addition to accelerometry. So far, this has not resulted in improvements in estimating EE. In the study of Colbert et al. (Table 2), AEE, as predicted by the SenseWear, showed a lower correlation with DLW-assessed AEE than only the steps from the SenseWear. In this case, the proprietary algorithm uses subject characteristics and input from different sensors (heat flux, skin temperature, galvanic skin response, accelerometer) which results in a worse correlation than using just 'steps' from the accelerometer (28). Furthermore, disadvantages of multiple sensor systems are that each sensor will have its inherent measurement error, that the risk of technical failure will increase, and wear ability will decrease.

\section{How to choose an accelerometer}

The choice of the most suitable accelerometer will depend on the research goal, the population being studied, the preferred outcome measures and the available budget. There is not a single accelerometer that can fulfil all requirements. If there is a need to differentiate between not just physical activity intensity but also activity type or postures, then a piezo-resistive or capacitive sensor is needed. These sensors will need the battery power and storage capacity for raw data collection over several days. Physical activity monitoring needs to be done over several days in order to get a good representation about the habitual physical activity pattern. In the elderly, it was shown that at least $3 \mathrm{~d}$ was necessary (50). In younger subjects, activity patterns often vary more substantially and a full week of monitoring may be advisable. Activity type recognition is hard to validate under daily life conditions, hence extensive laboratory validation is necessary. In addition, behaviour profiling usually becomes technically challenging when raw data over several days need to be processed. In specific situations, a multiple sensor system (such as the IDEEA) could be useful, allowing more extensive differentiation between different postures and/or activity types. For daily life, these systems are generally less suitable.

To assess daily life physical activities, validation against DLW is necessary. Ideally, the observation period is then the same for the accelerometer and DLW, which is not always the case in the studies included in Table 2. Even when no specific information about $\mathrm{EE}$ is required, the validation against DLW indicates whether the accelerometer has really captured body movement. When no relation between accelerometer output and $\mathrm{EE}$ is present, by definition the accelerometer has not properly measured physical activity.

\section{Conclusion}

In conclusion, an increasing number of accelerometers have been validated under free-living conditions. Performance of an accelerometer is best evaluated when the contribution of the accelerometer output itself (and any additional physiological data) is reported, independent of 
subject characteristics. The ability to store raw acceleration data further improves the possibility for more advanced data analysis by the researcher. Activity recognition has great potential to improve the assessment of physical activity-related health outcomes. So far, there is little evidence that adding other physiological measures such as HR significantly improves the estimation of EE.

\section{Conflict of interest statement}

There are no conflicts of interest.

\section{References}

1. Bouten CV, Koekkoek KT, Verduin M, Kodde R, Janssen JD. A triaxial accelerometer and portable data processing unit for the assessment of daily physical activity. IEEE Trans Biomed Eng 1997; 44: 136-147.

2. Plasqui G, Joosen AM, Kester AD, Goris AH, Westerterp KR. Measuring free-living energy expenditure and physical activity with triaxial accelerometry. Obes Res 2005; 13: 1363-1369.

3. Healy GN, Wijndaele K, Dunstan DW et al. Objectively measured sedentary time, physical activity, and metabolic risk: the Australian Diabetes, Obesity and Lifestyle Study (AusDiab). Diabetes Care 2008; 31: 369-371.

4. Owen N, Healy GN, Matthews CE, Dunstan DW. Too much sitting: the population health science of sedentary behavior. Exerc Sport Sci Rev 2010; 38: 105-113.

5. Caspersen CJ, Powell KE, Christenson GM. Physical activity, exercise, and physical fitness: definitions and distinctions for health-related research. Public Health Rep 1985; 100: 126-131.

6. Plasqui G, Westerterp KR. Physical activity assessment with accelerometers: an evaluation against doubly labeled water. Obesity (Silver Spring) 2007; 15: 2371-2379.

7. Bonomi AG, Plasqui G, Goris AH, Westerterp KR. Aspects of activity behavior as a determinant of the physical activity level. Scand J Med Sci Sports 2012; 22: 139-145.

8. Dugas LR, Carstens MA, Ebersole K et al. Energy expenditure in young adult urban informal settlement dwellers in South Africa. Eur J Clin Nutr 2009; 63: 805-807.

9. Ekelund U, Sarnblad S, Brage S, Ryberg J, Wareham NJ, Aman J. Does physical activity equally predict gain in fat mass among obese and nonobese young adults? Int J Obes (Lond) 2007; 31: $65-71$.

10. Fuller Z, Horgan G, O'Reilly LM, Ritz P, Milne E, Stubbs RJ. Comparing different measures of energy expenditure in human subjects resident in a metabolic facility. Eur J Clin Nutr 2008; 62: 560-569.

11. Gradmark A, Pomeroy J, Renstrom F et al. Physical activity, sedentary behaviors, and estimated insulin sensitivity and secretion in pregnant and non-pregnant women. BMC Pregnancy Childbirth 2011; 11: 44.

12. Jackson DM, Djafarian K, Stewart J, Speakman JR. Increased television viewing is associated with elevated body fatness but not with lower total energy expenditure in children. Am J Clin Nutr 2009; 89: 1031-1036.

13. Johannsen DL, DeLany JP, Frisard MI et al. Physical activity in aging: comparison among young, aged, and nonagenarian individuals. J Appl Physiol 2008; 105: 495-501.

14. Martin CK, Das SK, Lindblad L et al. Effect of calorie restriction on the free-living physical activity levels of nonobese humans: results of three randomized trials. J Appl Physiol 2011; 110: 956-963.

15. Nilsson A, Brage S, Riddoch C et al. Comparison of equations for predicting energy expenditure from accelerometer counts in children. Scand J Med Sci Sports 2008; 18: 643-650.

16. Reichert FF, Menezes AM, Kingdom Wells JC, Ekelund E, Rodrigues FM, Hallal PC. A methodological model for collecting high-quality data on physical activity in developing settings - the experience of the 1993 Pelotas (Brazil) Birth Cohort Study. J Phys Act Health 2009; 6: 360-366.

17. Rumo M, Amft O, Troster G, Mader U. A stepwise validation of a wearable system for estimating energy expenditure in fieldbased research. Physiol Meas 2011; 32: 1983-2001.

18. Wilkinson DM, Rayson MP, Bilzon JL. A physical demands analysis of the 24-week British Army Parachute Regiment recruit training syllabus. Ergonomics 2008; 51: 649-662.

19. Carter J, Wilkinson D, Blacker S et al. An investigation of a novel three-dimensional activity monitor to predict free-living energy expenditure. J Sports Sci 2008; 26: 553-561.

20. Pomeroy J, Brage S, Curtis JM, Swan PD, Knowler WC, Franks PW. Between-monitor differences in step counts are related to body size: implications for objective physical activity measurement. PLoS ONE 2011; 6: e18942.

21. Yang CC, Hsu YL. A review of accelerometry-based wearable motion detectors for physical activity monitoring. Sensors (Basel) 2010; 10: 7772-7788.

22. Assah FK, Ekelund U, Brage S, Wright A, Mbanya JC, Wareham NJ. Accuracy and validity of a combined heart rate and motion sensor for the measurement of free-living physical activity energy expenditure in adults in Cameroon. Int J Epidemiol 2011; 40: 112-120.

23. Brage S, Brage N, Franks PW, Ekelund U, Wareham NJ. Reliability and validity of the combined heart rate and movement sensor Actiheart. Eur J Clin Nutr 2005; 59: 561-570.

24. Arvidsson D, Slinde F, Hulthen L. Free-living energy expenditure in children using multi-sensor activity monitors. Clin Nutr 2009; 28: 305-312.

25. Johannsen DL, Calabro MA, Stewart J, Franke W, Rood JC, Welk GJ. Accuracy of armband monitors for measuring daily energy expenditure in healthy adults. Med Sci Sports Exerc 2010; 42: 2134-2140.

26. Skipworth RJ, Stene GB, Dahele M et al. Patient-focused endpoints in advanced cancer: criterion-based validation of accelerometer-based activity monitoring. Clin Nutr 2011; 30: 812 821.

27. Esliger DW, Rowlands AV, Hurst TL, Catt M, Murray P, Eston RG. Validation of the GENEA accelerometer. Med Sci Sports Exerc 2011; 43: 1085-1093.

28. Colbert LH, Matthews CE, Havighurst TC, Kim K, Schoeller DA. Comparative validity of physical activity measures in older adults. Med Sci Sports Exerc 2011; 43: 867-876.

29. Eiholzer U, Meinhardt U, Rousson V et al. Association between short sleeping hours and physical activity in boys playing ice hockey. J Pediatr 2008; 153: 640-645, 645.e1.

30. Jacobi D, Perrin AE, Grosman N et al. Physical activity-related energy expenditure with the RT3 and TriTrac accelerometers in overweight adults. Obesity (Silver Spring) 2007; 15: 950-956.

31. Zhang K, Werner P, Sun M, Pi-Sunyer FX, Boozer CN. Measurement of human daily physical activity. Obes Res 2003; 11: 33-40.

32. Bonomi AG, Plasqui G, Goris AH, Westerterp KR. Estimation of free-living energy expenditure using a novel activity monitor designed to minimize obtrusiveness. Obesity (Silver Spring) 2010; 18: $1845-1851$. 
33. John D, Freedson P. ActiGraph and Actical physical activity monitors: a peek under the hood. Med Sci Sports Exerc 2012; 44: S86-S89.

34. Assah FK, Ekelund U, Brage S et al. Predicting physical activity energy expenditure using accelerometry in adults from subSahara Africa. Obesity (Silver Spring) 2009; 17: 1588-1595.

35. Corder K, Brage S, Wright A et al. Physical activity energy expenditure of adolescents in India. Obesity (Silver Spring) 2010; 18: 2212-2219.

36. Maddison R, Jiang Y, Hoorn SV et al. Estimating energy expenditure with the RT3 triaxial accelerometer. Res Q Exerc Sport 2009; 80: 249-256.

37. Pietilainen KH, Kaprio J, Borg P et al. Physical inactivity and obesity: a vicious circle. Obesity (Silver Spring) 2008; 16: 409 414.

38. van der Kuip M, de Meer K, Westerterp KR, Gemke RJ. Physical activity as a determinant of total energy expenditure in critically ill children. Clin Nutr 2007; 26: 744-751.

39. Bonomi AG, Goris AH, Yin B, Westerterp KR. Detection of type, duration, and intensity of physical activity using an accelerometer. Med Sci Sports Exerc 2009; 41: 1770-1777.

40. Lof M. Physical activity pattern and activity energy expenditure in healthy pregnant and non-pregnant Swedish women. Eur J Clin Nutr 2011; 65: 1295-1301.

41. Healy GN, Matthews CE, Dunstan DW, Winkler EA, Owen N. Sedentary time and cardio-metabolic biomarkers in US adults: NHANES 2003-06. Eur Heart J 2011; 32: 590-597.

42. Bonomi AG, Plasqui G, Goris AH, Westerterp KR. Improving assessment of daily energy expenditure by identifying types of physical activity with a single accelerometer. J Appl Physiol 2009; 107: 655-661.

43. Antonsson EK, Mann RW. The frequency content of gait. J Biomech 1985; 18: 39-47.

44. Sun M, Hill JO. A method for measuring mechanical work and work efficiency during human activities. J Biomech 1993; 26: 229-241.

45. Heil DP. Estimating energy expenditure in wildland fire fighters using a physical activity monitor. Appl Ergon 2002; 33: 405413.

46. Matthews CE. Calibration of accelerometer output for adults. Med Sci Sports Exerc 2005; 37: S512-S522.

47. Westerterp KR, Brouns F, Saris WH, ten Hoor F. Comparison of doubly labeled water with respirometry at low- and highactivity levels. J Appl Physiol 1988; 65: 53-56.

48. Schoeller DA, Ravussin E, Schutz Y, Acheson KJ, Baertschi P, Jequier E. Energy expenditure by doubly labeled water: validation in humans and proposed calculation. Am J Physiol 1986; 250: R823-R830.

49. Westerterp KR. Diet induced thermogenesis. Nutr Metab (Lond) 2004; 1: 5.
50. Hart TL, Swartz AM, Cashin SE, Strath SJ. How many days of monitoring predict physical activity and sedentary behaviour in older adults? Int J Behav Nutr Phys Act 2011; 8: 62.

51. Corder K, Brage S, Ramachandran A, Snehalatha C, Wareham N, Ekelund U. Comparison of two Actigraph models for assessing free-living physical activity in Indian adolescents. J Sports Sci 2007; 25: 1607-1611.

52. Corder K, van Sluijs EM, Wright A, Whincup P, Wareham NJ, Ekelund U. Is it possible to assess free-living physical activity and energy expenditure in young people by self-report? Am J Clin Nutr 2009; 89: 862-870.

53. Krishnaveni GV, Veena SR, Kuriyan R et al. Relationship between physical activity measured using accelerometers and energy expenditure measured using doubly labelled water in Indian children. Eur J Clin Nutr 2009; 63: 1313-1319.

54. Rothney MP, Brychta RJ, Meade NN, Chen KY, Buchowski MS. Validation of the ActiGraph two-regression model for predicting energy expenditure. Med Sci Sports Exerc 2010; 42: 17851792.

55. Copland L, Liedman B, Rothenberg E, Ellegard L, Hustvedt BE, Bosaeus I. Validity of the ActiReg system and a physical activity interview in assessing total energy expenditure in longterm survivors after total gastrectomy. Clin Nutr 2008; 27: 842848.

56. Hustvedt BE, Christophersen A, Johnsen LR et al. Description and validation of the ActiReg: a novel instrument to measure physical activity and energy expenditure. Br J Nutr 2004; 92: 1001-1008.

57. van Hees VT, Renstrom F, Wright A et al. Estimation of daily energy expenditure in pregnant and non-pregnant women using a wrist-worn tri-axial accelerometer. PLoS ONE 2011; 6: e22922. 58. Kumahara H, Schutz Y, Ayabe M et al. The use of uniaxial accelerometry for the assessment of physical-activity-related energy expenditure: a validation study against whole-body indirect calorimetry. Br J Nutr 2004; 91: 235-243.

59. Ohkawara K, Ishikawa-Takata K, Park JH, Tabata I, Tanaka S. How much locomotive activity is needed for an active physical activity level: analysis of total step counts. BMC Res Notes 2011; 4: 512 .

60. Rowlands AV, Thomas PW, Eston RG, Topping R. Validation of the RT3 triaxial accelerometer for the assessment of physical activity. Med Sci Sports Exerc 2004; 36: 518-524.

61. Reilly JJ, Kelly LA, Montgomery C et al. Validation of Actigraph accelerometer estimates of total energy expenditure in young children. Int J Pediatr Obes 2006; 1: 161-167.

62. Butte NF, Wong WW, Adolph AL, Puyau MR, Vohra FA, Zakeri IF. Validation of cross-sectional time series and multivariate adaptive regression splines models for the prediction of energy expenditure in children and adolescents using doubly labeled water. J Nutr 2010; 140: 1516-1523. 